\title{
ASSOCIATION BETWEEN OVARIAL CYST AND INFERTILITY IN WOMEN OF CHILDBEARING AGE
}

\author{
Nara Lintan Mega Puspita \\ Diploma Program in Midwivery, Faculty of Public Health, Kadiri University
}

\begin{abstract}
Background: Infertility is one of public health importance. One of the conditions that may cause infertility is ovarial cyst. Generally couples do not know if their partners have infertility and causes of infertility. One of the causes of infertile women is the presence of ovarian cysts. This study aimed to determine the relationship between ovarian cysts with infertile incidence in women of childbearing age in RS Aura Syifa Kediri, East Java.

Subjects and Method: This was a cross sectional method. A subject of 234 people selected for this study by simple random sampling. The dependent variable was infertile incidence. The independent variable was ovarian cyst. The data was collected by checklist sheet. The infertility data and history of ovarian cysts were collected from medical records data at RS Aura Syifa Kediri. The data was analyzed by Chi Square.

Results: Study subjects who suffered from ovarian cysts were 101 people (43.2\%) and those with infertility were 109 people (46.6\%), and it was statistically significant $(\mathrm{p}<0.001)$. The results showed a strong and positive relationship between ovarian cyst and infertile incidence in women of childbearing age.

Conclusion: There is a positive relationship between ovarian cyst with infertile incidence in women of childbearing age.
\end{abstract}

Keywords: infertility, ovarian cyst, women of childbearing age

Correspondence: Nara Lintan Mega Puspita. Diploma Program in Midwivery, Faculty of Public Health, Kadiri University, Kediri, East Java. 